\title{
Emergency peripartum hysterectomy in a tertiary hospital in Antananarivo, Madagascar
}

\author{
Ratsiatosika A. Tanjona ${ }^{1 *}$, Randriamahavonjy Romuald ${ }^{2}$, Ratongasoa Mahefa ${ }^{2}$, Housni I. A. ${ }^{2}$, \\ Rakotonirina A. Martial'2, Randria J. Mahenina' ${ }^{2}$, Rakotonirina Ando-Miora ${ }^{2}$, \\ Andrianampanalinarivo H. Rakotovao ${ }^{2}$
}

\begin{abstract}
${ }^{1}$ Department of Public Health, Faculty of Medicine, Antananarivo, Madagascar
${ }^{2}$ Department of Obstetrics and Gynecology, Soavinandriana Hospital Center, Faculty of Medicine Antananarivo, Antananarivo, Madagascar
\end{abstract}

Received: 02 September 2018

Accepted: 28 September 2018

\author{
*Correspondence: \\ Dr. Ratsiatosika A. Tanjona, \\ E-mail: ratsiatosika.tanjona@gmail.com
}

Copyright: () the author(s), publisher and licensee Medip Academy. This is an open-access article distributed under the terms of the Creative Commons Attribution Non-Commercial License, which permits unrestricted non-commercial use, distribution, and reproduction in any medium, provided the original work is properly cited.

\begin{abstract}
Background: Postpartum hemorrhage is one of the leading causes of maternal death in the entire world. It affects $10 \%$ of deliveries. Emergency peripartum hysterectomy (EPH)defined as a lifesaving procedure involving the removal of the uterus to treat severe postpartum hemorrhage is one of the last-resort treatments for severe postpartum hemorrhage in case of failure of other techniques. Through this study, we aimed both to describe the epidemiological profile, to determine the etiologies, and maternal complications of EPH.

Methods: It is about a descriptive retrospective study from January 1st, 2016 to January 1st, 2017 at the Befelatanana University Hospital of Obstetrics and Gynecology. We included all patients who underwent Emergency peripartum hysterectomy after 22 weeks of Amenorrhea (WA) regardless of the delivery route in the centre. We used the R software for the statistical analysis of the results.

Results: We had 31 cases of EPH during this period with a prevalence of $0.44 \%$. The average age was $26.38 \pm 5.61$ years. Mean gestational age was $37 \pm 3.59$ weeks of amenorrhea. In the $83.87 \%$ of cases, the patient received less than four prenatal consultations. Patients were referred in $45.16 \%$ of the cases. The delivery route was by cesarean section in $48.39 \%$ of cases. Eleven patients $(35.48 \%$ ) received a blood transfusion. Hysterectomy was subtotal in $96.77 \%$ of the cases. We had five $(16.13 \%)$ maternal deaths during the study period. The leading cause of death was hemorrhagic shock $(80 \%)$. The etiology of hysterectomy was dominated by uterine atony complicated by hemorrhage $(48.39 \%)$, followed by retroplacental hematoma $(25.81 \%)$ and uterine rupture $(22.58 \%)$.

Conclusions: EPH still holds its place in the management of postpartum hemorrhage in Madagascar. Maternal mortality remains high. Uterine atony was the most common indication for EPH. The prevention of postpartum hemorrhage by management of the third stage of labour should be carried out by any health actor.
\end{abstract}

Keywords: Emergency peripartum hysterectomy, Postpartum haemorrhage, Uterine atony, Uterine rupture

\section{INTRODUCTION}

Postpartum hemorrhage is one of the leading causes of maternal death in the entire world. ${ }^{1}$ It affects $10 \%$ of deliveries. This is about the leading cause of admission to intensive care unit and maternal morbidity. ${ }^{2}$
Hysterectomy is one of the last-resort treatments for severe postpartum hemorrhage in case of failure of other techniques. Emergency peripartum hysterectomy (EPH) is defined as a lifesaving procedure involving the removal of the uterus to treat severe postpartum hemorrhage. ${ }^{3}$ Although its frequency has declined significantly in 
developed countries over the past decade, this technique still plays an important role in the management of postpartum hemorrhage in developing countries. ${ }^{4,5}$ In developed countries, placenta accreta becomes the first cause of emergency peripartum hysterectomy. It is due to the increased frequency of cesarean section and decreased incidence of uterine atony through the use of uterotonic drugs, improved conservative techniques and embolization. ${ }^{3}$ In Madagascar, the reduction of maternal mortality caused by postpartum hemorrhage remains a major challenge. Emergency peripartum hysterectomy is the last therapeutic means of postpartum hemorrhage in the local protocol. The ineffectiveness of conservative treatments after 30 minutes of management is the indication of an emergency peripartum hysterectomy in our protocol. Decisions making are difficult because they are considered as mutilation. But the EPH is often performed in the framework of the obstetric emergency because we do not have any alternative technique like the embolization of the uterine artery. Very few studies from developing countries are interested in this matter especially in Madagascar.

What motivated us to conduct this study is both to describe the epidemiological profile, to determine the etiologies, and maternal complications of EPH.

\section{METHODS}

This is a retrospective descriptive study, conducted at the Befelatanana University Hospital Centre of Gynecology and Obstetrics between the periods from January 1, 2016 to January 31, 2017.

We included all patients who underwent Emergency peripartum hysterectomy after 22 weeks of Amenorrhea (WA) regardless of the delivery route in the centre. Incomplete data, EPH referred by other centers were excluded.

Authors studied the following parameters:

- Maternal socio-demographic parameters: maternal age, marital status, occupation, gestational status, parity, number of prenatal consultations, attempted delivery outside the centre, history of cesarean section

- Obstetrical parameters: term of pregnancy, uterine height, existence of pregnancy pathology, duration of labour, use of oxytocin, fetal presentation, route of delivery

- Maternal issue: quantity of blood loss, maternal death, cause of maternal death, type of hysterectomy, blood transfusion

- Cause of hysterectomy

- Neonatal issue: average birth weight, Apgar score at first and fifth minute, number of neonatal asphyxias, number of neonatal Intensive care unit transfers, number of deaths in utero.
Quantitative variables were expressed on average and their standard deviations and qualitative variables as percentages. Authors used the $\mathrm{R}$ software for the statistical analysis of the results.

\section{RESULTS}

During this period, we recorded 31 cases of EPH out of 6951 births. Which is a prevalence of $0.44 \%$. The average age was $26.38 \pm 5.61$ years old. More than half of the patients were between the ages of 25 and $35(51.61 \%)$ and $45.16 \%$ were under 25 years old. A quarter of these patients were married.

Three quarters worked in the primary sector. The average parity was $1.7 \pm 1.75$, a quarter of which was nulliparous. In the $83.87 \%$ of cases, the patient received less than four prenatal consultations. Patients were referred in $45.16 \%$ of the cases (Table 1).

Table 1: Maternal characteristics.

\begin{tabular}{|c|c|c|}
\hline \multicolumn{3}{|l|}{ Variable } \\
\hline \multirow{3}{*}{ Age } & Mean \pm SD (years) & $26.38 \pm 5,61$ \\
\hline & Min & 19 \\
\hline & Max & 40 \\
\hline \multirow{5}{*}{ Marital status } & Single & $9(29.03 \%)$ \\
\hline & Concubine & $4(12.90 \%)$ \\
\hline & Married & $9(29.03 \%)$ \\
\hline & Divorced & $1(3.23 \%)$ \\
\hline & Widow & $1(3.23 \%)$ \\
\hline \multirow{4}{*}{ Profession } & Housewife & $2(6.45 \%)$ \\
\hline & Primary sector & $24(77.42 \%)$ \\
\hline & Secondary sector & $3(9.68 \%)$ \\
\hline & Tertiary sector & $2(6.45 \%)$ \\
\hline \multirow{3}{*}{ Gestity } & Mean \pm SD & $2.67 \pm 0.76$ \\
\hline & Min & 1 \\
\hline & Max & 9 \\
\hline \multirow{5}{*}{ Parity } & Mean \pm SD & $1.7 \pm 1.75$ \\
\hline & Nullipara & $8(25.81 \%)$ \\
\hline & Primipara & $9(29.03 \%)$ \\
\hline & Paucipara & $13(41.94 \%)$ \\
\hline & Multipara & $1(3.23 \%)$ \\
\hline \multirow{2}{*}{$\begin{array}{l}\text { Number of } \\
\text { antenatale care } \\
\text { (ANC) }\end{array}$} & Mean \pm SD & $2.47 \pm 0.94$ \\
\hline & $<4(\mathrm{ANC})$ & $26(83.87 \%)$ \\
\hline \multicolumn{2}{|c|}{ Referred after vaginal birth attempt } & $14(45.16 \%)$ \\
\hline \multicolumn{2}{|l|}{ Scarred uterus } & $1(3,23 \%)$ \\
\hline
\end{tabular}

Regarding obstetrical parameters, the average gestational age was $37 \pm 3.59$ weeks. Six patients have an induced labour, three with prostaglandins and the rests with oxytocin. The average duration of labour was $7.88 \pm 2.54$ hours.

Five patients received oxytocin during labour. The fetal presentation was cephalic in anterior variety in $64.52 \%$ of cases. 
The average duration of membrane rupture was $4.75 \pm 3.77$ hours. The delivery route was by cesarean section in $48.39 \%$ of cases (Table 2).

Table 2: Obstetrical parameters.

\begin{tabular}{|lll|}
\hline Variable & & \\
Gestational age (week & Mean \pm SD & $37 \pm 3.59$ \\
of gestation) & Min & 24 \\
\hline \multirow{2}{*}{$\begin{array}{l}\text { Labour induction } \\
\text { Max }\end{array}$} & 41 \\
\hline Preeclampsia & Mo induction & $25(80.65 \%)$ \\
\hline Uterine height & Oxytocine & $3(9.68 \%)$ \\
\hline Duration of labour (h) & Mean \pm SD & $3(19.35 \%)$ \\
\hline Oxytocin use & Mean \pm SD & $7.88 \pm 2.54$ \\
\hline \multirow{2}{*}{ Presentation } & Unknown & $5(16.13 \%)$ \\
\cline { 2 - 3 } & $\begin{array}{l}\text { Cephalic } \\
\text { anterior }\end{array}$ & $20(29.03 \%)$ \\
\hline $\begin{array}{l}\text { Cephalic } \\
\text { posterior }\end{array}$ & $1(3.23 \%)$ \\
\hline $\begin{array}{l}\text { Shoulder } \\
\text { presentation }\end{array}$ & $1(3.23 \%)$ \\
\hline $\begin{array}{l}\text { Duration of membrane } \\
\text { rupture }\end{array}$ & $\begin{array}{l}\text { Mean } \pm \text { sd } \\
\text { Delivery route }\end{array}$ & $4.75 \pm 3.77$ \\
\hline $\begin{array}{l}\text { Vaginal birth } \\
\text { Cesarean }\end{array}$ & $14(45.16 \%)$ \\
\hline $\begin{array}{l}\text { section } \\
\text { Laparotomy }\end{array}$ & $7(25.81 \%)$ \\
\hline $\begin{array}{l}\text { Instrumental } \\
\text { extraction }\end{array}$ & $2(6.45 \%)$ \\
\hline
\end{tabular}

Concerning maternal issue, the average blood loss was $947 \pm 433 \mathrm{ml}$. Eleven patients $(35.48 \%)$ received a blood transfusion.

Table 3: Maternal outcomes.

\begin{tabular}{|c|c|c|}
\hline \multicolumn{3}{|l|}{ Variables } \\
\hline $\begin{array}{l}\text { Volume of } \\
\text { blood loss }(\mathrm{ml})\end{array}$ & Mean \pm SD & $947 \pm 433$ \\
\hline \multirow{2}{*}{$\begin{array}{l}\text { Cause of } \\
\text { maternal death } \\
\mathrm{N}=5(100 \%)\end{array}$} & Hemorragic shock & $4(80 \%)$ \\
\hline & $\begin{array}{l}\text { Abruptio placenta } \\
\text { complicated by dic }\end{array}$ & $1(20 \%)$ \\
\hline \multirow{2}{*}{$\begin{array}{l}\text { Type of } \\
\text { hysterectomy }\end{array}$} & Total & $1(3,23 \%)$ \\
\hline & Subtotal & $30(96,77 \%)$ \\
\hline \multicolumn{2}{|c|}{ Blood transfusion } & $11(35,48 \%)$ \\
\hline \multicolumn{2}{|l|}{ Maternal death } & $5(16,13 \%)$ \\
\hline
\end{tabular}

Table 4: Neonatal outcomes.

\begin{tabular}{|lll|}
\hline Variables & & \\
\hline Birth weight (gram) & Mean \pm SD & $2797.5 \pm 734.6$ \\
\hline Apgar M1 & Mean \pm SD & $7.07 \pm 2.87$ \\
\hline Apgar M5 & Mean \pm SD & $9.61 \pm 2.87$ \\
\hline Neonatal asphyxia & & $1(3,23 \%)$ \\
\hline NICU transfer & & $7(22,58 \%)$ \\
\hline Intra-uterine fetal death & & $9(29,03 \%)$ \\
\hline
\end{tabular}

Hysterectomy was subtotal in $96.77 \%$ of the cases. Authors had five $(16.13 \%)$ maternal deaths during the study period. The leading cause of death was hemorrhagic shock (80\%) (Table 3).

The neonatal issue was traced by a rate of death in utero in $29.03 \%$ and transfer to neonatal intensive care unit in $22.58 \%$. The average birth weight was $2797.5 \pm 734.6 \mathrm{~g}$ (Table 4).

The etiology of hysterectomy was dominated by uterine atony complicated by hemorrhage $(48.39 \%)$, followed by retroplacental hematoma $(25.81 \%)$ and uterine rupture (22.58\%). (Figure 1).

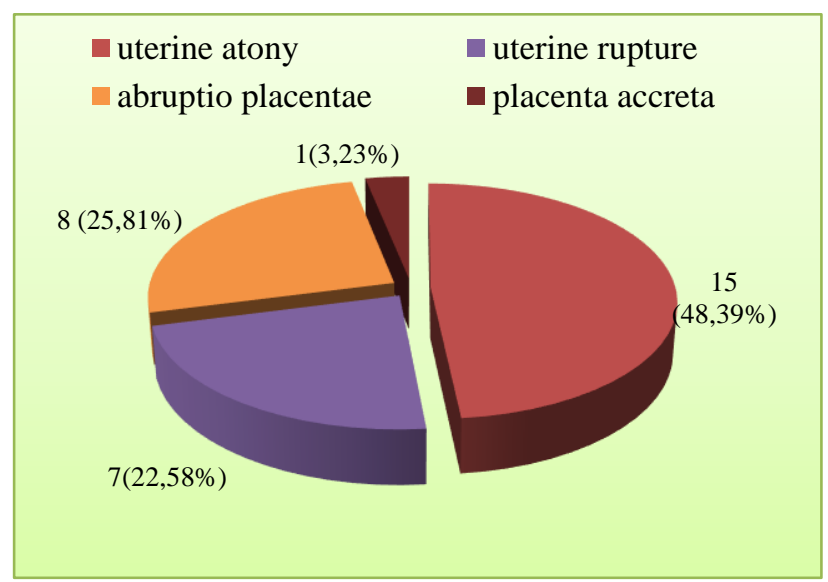

Figure 1: Etiology of emergency peripartum hysterectomy.

\section{DISCUSSION}

In the whole world, the prevalence of hemostasis hysterectomy varies between 0.2 and 5.4\%. ${ }^{6,7}$ Authors had a prevalence of $0.44 \%$. This rate is higher compared to a study conducted in the East Coast of Madagascar $(0.14 \%) .^{8}$ This high frequency could be explained by the fact that our centre is a reference centre in a most populous city in Madagascar. Present study is identical to that of the developing countries. In India this rate varies from $0.12 \%$ to $0.57 \% .^{9-13}$ In Africa, this prevalence varies between $0.2 \%$ and $0.62 \% .{ }^{14-16}$ The highest frequency is reported by Nayama et al, in Nigeria. He reported a very high rate of EPH of $1.25 \% .^{5}$ In developed countries, the rate varies from 5.6 to $22 / 10,000$ births. ${ }^{3,17-19}$ The frequency of hemostasis hysterectomy has decreased tenfold in the last 30 years in these countries. ${ }^{20}$ Developing countries have four times risks higher (relative risk 4.2, 95\% CI 4.0-4.5). ${ }^{7}$ The development of interventional radiology techniques tends to decrease this frequency in developed countries. The embolization of the uterine arteries has efficiency between 70 and $100 \% .{ }^{20}$ In our centre, this technique is not available. The average age of our patients was $26.38 \pm 5.61$ years. This is identical to a study conducted in the eastern part of Madagascar at the University Hospital Centre of Toamasina. The average age was 26.3 years old. ${ }^{8}$ This 
age is relatively young compared to other studies in Africa which average age varies between 28.1 and 32.76 years old. ${ }^{5,15,21,22}$. In India, the average age varies between 29.9 years old and 30.25 years old. ${ }^{12,23}$ In developed countries, the average age varies between 34.47 and 35.2 years old. ${ }^{19,24}$ A recent meta-analysis found an average maternal age between 26.2 and 37.9 years old. ${ }^{7}$ The Age difference could be explained by the early pregnancy of the Malagasy girl. Indeed, Madagascar is among the countries where the fertility of women is earlier. There is an early fertility of $148 \%$ to $15-19$ years old and a maximum fertility reached in 20-24 years old with a rate of $2.34 \% .{ }^{25}$ In present study, more than half of the patients were between 25 and 35 years old (51.61\%). Studies have shown that as the age increases, the risk of hemostasis hysterectomy is high. ${ }^{16,26}$

It has been reported that multiparas were most at risk for hemostasis hysterectomy. ${ }^{7,16}$ In the present context, it is the pauciparas and the primiparas who are the most affected. Present study is similar to what Mayadeo et al found in India and Abasiattai in Nigeria. ${ }^{12,14}$ In this study, uterine atony and uterine rupture are the main causes. Primiparous and pauciparous women who have attempted vaginal delivery outside a health centre are the most affected. These patients had prolonged labour and resulted to uterine rupture increasing the frequency of hemostasis hysterectomy in this group of patients. A quarter of our patients are nulliparous. To our knowledge, we have the highest nulliparous rate that required hemostatic hysterectomy for postpartum hemorrhage management. This testifies to the seriousness of the bleeding where hysterectomy remains the last resort to save the maternal life.

Patients received less than four prenatal consultations in $83.87 \%$ of the cases. Our observation is identical to that of the developing countries. Most patients were not followed up correctly or had no prenatal consultation. 5 , 8,14-16 According to Omole-Ohonsi et al, the absence of prenatal consultation leads to a nine-fold higher risk of hemostasis hysterectomy $(\mathrm{OR}=9.1,95 \%$ CI [3.624.9]). ${ }^{16}$ Risk factors for postpartum hemorrhage may be identified during follow-up. Preventive measures can be used at the time of delivery, reducing the risk of hemostasis hysterectomy. The identification of fetopelvic disproportions, uterine scar, and placentas prævia during the prenatal consultation identify the risk factors for uterine rupture and placenta accreta.

Most patients (45.16\%) were referred cases. It is a failure of attempting vaginal delivery from another center, most often after labour and prolonged expulsive efforts. This results in delayed care, transportation and access to care promoting the onset uterine rupture or uterine atony. Doddamani et al found a similar result. ${ }^{13}$ The delivery route was predominantly abdominal (cesarean section and laparotomy). Our result joins the data of the literature. EPH was performed after abdominal delivery. This frequency varies from $66.7 \%$ to $96.4 \% .^{5,14,19,21-23}$
According to certain authors, cesarean sections are the source of hemorrhages. ${ }^{26-28}$ In present study, the retroplacental hematoma, the case of placenta accreta, were already, themselves, risk factors for the hemorrhage of delivery.

Regarding maternal issue, the average blood loss was $947 \pm 433 \mathrm{ml}$. A multicentre study in Africa and Asia showed that more than half of the patients had less than $1000 \mathrm{ml}$ of blood loss. ${ }^{28}$ Subtotal hysterectomy is high in developing countries as well as in developed countries. It went from $94.8 \%$ to $47 \% .^{7}$ In $96.77 \%$ of the cases in present study, the hysterectomy was subtotal. Another study in Madagascar reported $81 \%$ of subtotal hysterectomy. Present results are identical to African countries. This rate varies between $65.85 \%$ and $92.8 \% .^{5,14-16,22}$ In developed countries, this rate ranges from $54.9 \%$ to $87 \%$ of subtotal hysterectomy cases. ${ }^{29}$ In India, this rate varies between $26 \%$ and $88.09 \% .{ }^{11,12,23,30}$ Total hysterectomy is indicated for placenta accreta, which is the main indication in developed countries. Indeed, subtotal hysterectomy is indicated if the source of the bleeding is upstream of the lower segment. On the other hand, in case of placenta praevia or bleeding of cervical origin or vaginal tear, a total hysterectomy will be performed. ${ }^{31}$ In our setting, the only total hysterectomy performed was on placenta accreta after cesarean section.

Authors had $16.13 \%$ maternal death. Abasiattai and Omole-Ohonsi found identical results $(13.3 \%-14.3 \%$ respectively). ${ }^{14,16}$ This was twice as high as what Randriambelomanana et al found in Toamasina (7.69\%) 8. In India, maternal mortality ranges from $2.2 \%$ to $16.7 \%{ }^{9-12,23,30}$ Studies in Africa have found a higher frequency. Obiecchina found up to $31 \%$ of maternal deaths, Nayama found $21.95 \%$ of deaths. ${ }^{5,15}$ According to the study woman trial, the mortality rate secondary to hysterectomy in Africa remains very high. This rate is three times higher than in developed countries ( $20 \%$ vs. $7 \%) .{ }^{28}$ In developed countries, maternal deaths are very low $(0-5.9 \%)$ with an average of $3 \%$ (4.3\% standard deviation). ${ }^{3,18,19,32}$

It is difficult to differentiate whether maternal deaths are due to hysterectomy or the causal pathology. In our context, maternal mortality was due to hemorrhagic shock in $80 \%$ of cases, followed by disseminated intravascular coagulopathy (DIC) (20\%). According to a meta-analysis in 2010, the leading cause of death was similar. Hemorrhagic shock accounted for $53.8 \%$ of cases, followed by DIC $(26.9 \%) .{ }^{33}$ In developing countries, hypovolemic shock and DIC remain the leading causes of death after hysterectomy. ${ }^{5,15}$ The lack of available blood products tends to increase maternal mortality. In this study, only 11 patients received an emergency transfusion. Almost all of our patients needed it. Improvements can be made to reduce maternal mortality. Improved care, in medical evacuation, medicalization of transport, availability of blood 
products, improvement of the technical intensive care unit platform, good coordination of the health care team (obstetrician, intensive care agent, anesthetist, nurse) would be necessary.

We have a high rate in utero fetal death $(29.03 \%)$. The causal pathology of hysterectomy is a source of fetal mortality in our context. Severe retroplacental hematoma and uterine rupture increase in utero mortality. In Africa, perinatal death varies between $18.8 \%$ and $81 \% .^{5,14,21,22}$ This mortality rate can be as high as 64 to $81 \%$ in the literature. This high perinatal mortality is mainly observed in case of uterine rupture and retroplacental hematoma. ${ }^{5,8,13,14}$ In developed countries, this rate varies between $3.9 \%$ and $5.88 \% .^{18,19}$

Uterine atony, retroplacental hematoma, uterine rupture remains the first indications of hemostatic hysterectomy in our context. Present study is identical to what found in Africa. These three obstetric pathologies are the main indications..$^{5,14,16,22}$ A modification of the indication has been noted during the last 30 years. ${ }^{3,20}$ In the literature, placental insertion abnormalities remain the first indication of hemostasis hysterectomy. ${ }^{7}$ This frequency of placenta accreta is due in large part to the increase in the frequency of cesarean section. ${ }^{3,20}$ We have fifteen cases $(48.39 \%)$ of hemostasis hysterectomy secondary to uterine atony. In developed countries, this indication has clearly decreased. The more satisfactory management of uterine atony by medical treatment, surgery or interventional radiology partly explains this finding. ${ }^{3,20}$ In present study, these patients were referred, the most often after prolonged labour. Improvements can be made to improve maternal health. Management of the third phase of labour should be followed with oxytocin-injected delivery upon delivery of the anterior shoulder. The storage conditions of oxytocin must be respected to avoid the reduction of the active ingredient. The use of prostaglandins and ergometrine is an alternative to oxytocin. Uterotonic medication endowment such as sulprostone and carbetocin would reduce the frequency of hemostasis hysterectomy. Mechanical means such as Bakri's balloon and tamponade condom can be used.

\section{CONCLUSION}

To conclude, EPH still holds its place in the management of postpartum hemorrhage in Madagascar and is associated with a high maternofetal mortality rate. Its learning training to future obstetricians and surgeons is a necessity to reduce the maternal mortality rate in Madagascar. The prevention of postpartum hemorrhage by management of the third stage of labour should be carried out by any health actor. Improving management (uterotonics, mechanical, and conservative surgery) is an interesting prospect for reducing the frequency of hemostasis hysterectomy. Improved intensive care and the availability of blood products would reduce the mortality rate secondary to hemostasis hysterectomy.
Funding: No funding sources

Conflict of interest: None declared

Ethical approval: The study was approved by the Institutional Ethics Committee

\section{REFERENCES}

1. Goffinet F. Hémorragies du post-partum immédiat : méthode utilisée et questions abordées. J Gynecol Obstet Biol Reprod (Paris) 2004;33(8 Suppl):4S74S8

2. Deneux TC, Bonnet MP, Tort J. Epidemiology of postpartum haemorrhage. J Gyneco Obstet Biol Reprod. 2014;43(10):936-50.

3. Macharey G, Ulander VM, Kostev K, Tommiska MV, Ziller V. Emergency peripartum hysterectomy and risk factors by mode of delivery and obstetric history: a 10-year review from Helsinki University Central Hospital. J. Perinat. Med. 2015;43(6):72128.

4. Salvat J, Schmidt MH, Guilbert M, Martino A. Vascular ligation in obstetrics in severe haemorrhages of delivery: review of the literature. $\mathbf{J}$ Gynecol Obstet Biol Reprod 2002;31:629-39,

5. Nayama M, Moulaye AA, Djibrill B, Garba M, Idi $\mathrm{N}$, Boukerrou M. Haemostasis hysterectomies in under-equipped countries: a vital gesture. Prospective study in a maternity hospital in Niger. Gynecol Obstet Fertil. 2006;34(10):900-5

6. Flood KM, Said S, Geary M, Robson M, Fitzpatrick $\mathrm{C}$, Malone FD. Changing trends in peripartum hysterectomy over the last 4 decades. Am J Obstet Gynecol. 2009;200(6):632-e1.

7. Van den Akker T, Brobbel C, Dekkers OM, Bloemenkamp KWM. Prevalence, Indications, Risk Indicators, and Outcomes of Emergency Peripartum Hysterectomy Worldwide. A Systematic Review and Meta-analysis. Obstet Gynecol. 2016;128(6):128194.

8. Randriambelomanana JA, Botolahy ZA, Rakotoarivony ST, Herinirina SAE, Rasataharifetra H, Ratsivalaka R. Obstetric hysterectomies performed in the service of Maternity of Toamasina University Hospital Madagascar. RARMU.2011; 3(1):8-11

9. Shirodker SD, Pandey A, Yadav S. Emergency obstetric hysterectomy: review at a tertiary care hospital. Int J Reprod Contracept Obstet Gynecol 2016;5(11):3811-4.

10. Sharma B, Saxena N, Gupta V. A retrospective study of emergency obstetric hysterectomy in a tertiary care center for a period of 5 years. Int J Reprod Contracept Obstet Gynecol. 2016;5(11):3778-81.

11. Bhagat M, MoitraB. Emergency peripartum hysterectomy: a retrospective analysis in a tertiary care hospital in Jharkhand, India Int $\mathbf{J}$ Reprod Contracept Obstet Gynecol 2018;5(9):3112-5.

12. Mayadeo NM, Swaminathan G. Obstetric hysterectomy: analysis of 50 cases at a tertiary care 
hospital. Int J Reprod Contracept Obstet Gynecol 2018;7(7):2882-7.

13. Doddamani U, Rampure N, Kulkarni S, Patil S, Tambre N. Emergency obstetric hysterectomy: a lifesaving procedure. Int J Reprod Contracept Obstet Gynecol. 2018;7(5):1876-9.

14. Abasiattai AM, Umoiyoho AJ, Utuk NM, InyangEtoh EC, Asuquo OP. Emergency peripartum hysterectomy in a tertiary hospital in southern Nigeria. Pan Afr Med J. 2013;15:60.

15. Obiechina N, Eleje GU, Ezebialu IU, Okeke C, Mbamara SU. Emergency peripartum hysterectomy in Nnewi, Nigeria: A 10-year review. Niger J Clin Pract . 2012;15(2):168-71

16. Omole-Ohonsi A, Olayinka HT. Emergency Peripartum Hysterectomy in a Developing Country. J Obstet Gynaecol Can. 2012;34(10):954-60.

17. Bobelon C, Ortiz AB, Schiff MA, Reed SD. Factors Associated With Peripartum Hysterectomy. Obstet Gynecol. 2009;114(1):115-23.

18. Habek D, Bečarević R. Emergency Peripartum Hysterectomy in a Tertiary Obstetric Center: 8-Year Evaluation. Fetal Diagn Ther. 2007;22(2):139-42.

19. D'Arpe S, Franceschetti S, Corosu R, Palaia I, Di Donato V, Perniola R, et al. Emergency peripartum hysterectomy in a tertiary teaching hospital: a 14year review. Arch Gynecol Obstet. 2014;291(4):8417.

20. Sergent F, Resch B, Verspyck E, Rachet B, Clavier E, Marpeau L. Serious haemorrhages of delivery: should we bind, hysterectomize or embolize? Gynecol Obstet Fertil. 2004;32(4):320-9

21. Allam S, Gomma IA, Fathi M, Sukkar M. Incidence of emergency peripartum hysterectomy in Ain-shams University Maternity Hospital, Egypt: a retrospective study. Arch Gynecol Obstet. 2014;290(5):891-6.

22. Akintayo AA, Olagbuji BN, Aderoba AK, Akadiri O, Olofinbiyi A, Bakare B. Emergency Peripartum Hysterectomy: A Multicenter Study of Incidence, Indications and Outcomes in Southwestern Nigeria. Matern Child Health J. 2016;20(6):1230-6.

23. Tahmina S, Daniel M, Gunasegaran P, Emergency Peripartum Hysterectomy: A 14-Year Experience at a Tertiary Care Centre in India. J Clin Diagn Res. 2017;11(9):8-11.

24. Tapisiz L, Altinbas SK, Yirci B, Cenksoy P, Kaya AE, Dede S. Emergency peripartum hysterectomy in a tertiary hospital in Ankara, Turkey: a 5-year review. Arch Gynecol Obstet. 2012;286(5):1131-4.
25. INSTAT MI. Madagascar Demographic and Health Survey 2008-2009. Antananarivo: INSTAT and ICF Macro. 2010.

26. Friedman AM, Wright JD, Ananth CV, Siddiq Z, D'alton ME, Bateman BT. Population-based risk for peripartum hysterectomy during low- and moderaterisk delivery hospitalizations. Am J Obstet Gynecol 2016.215(5):640-e1.

27. Zhang Y, Yan J, Han Q, Yang T, Cai L, Fu Y et al. Emergency obstetric hysterectomy for lifethreatening postpartum hemorrhage A 12-year review. Med. 2017;96:45.

28. Huque S, Roberts I, Fawole B, Chaudhri R, Arulkumaran S, Shakur-Still H. Risk factors for peripartum hysterectomy among women with postpartum haemorrhage: analysis of data from the WOMAN trial. BMC pregnancy and childbirth. 2018;18(1):186.

29. Özcan HC, Balat O, Tepe NB, Sucu S. Emergency peripartum hysterectomy: single center ten-year experience. J Mater Fetal Neonat Med. 2016. 30(23):2778-83;

30. Gupta T, Gupta S, Deepika, Gupta N. Changing trends in incidence, type, indication and maternal outcome of peripartum hysterectomy over 10 years at a tertiary care centre. Int J Reprod Contracept Obstet Gynecol. 2017;6(6):2216-21.

31. Sebghati M, Chandraharan E. An update on the risk factors for and management of obstetric haemorrhage. Women's Health. 2017;13(2):1-7.

32. Cara Z, Thompson EL, O'Rourke K, Nembhard WN. Cesarean section and the risk of emergency peripartum hysterectomy in high-income countries: a systematic review. Arch Gynecol Obstet. 2015;292(6):1201-15.

33. Rossi AC, Lee RH, Chmait RH. Emergency postpartum hysterectomy for uncontrolled postpartum bleeding: a systematic review. Obstet Gynecol. 2010;115(3):637-44.

Cite this article as: Tanjona RA, Romuald R, Mahefa R, Housni IA, Martial RA, Mahenina RJ, et al. Emergency peripartum hysterectomy in a tertiary hospital in Antananarivo, Madagascar. Int J Reprod Contracept Obstet Gynecol 2018;7:4752-7. 